\title{
Danos a um Projeto de Vida?
}

\author{
Denise Sá Vieira Carrá \\ Mestre em Direito pela UFC. Professora da FA7. \\ dsavieira@yahoo.com.br
}

\section{Bruno Leonardo Câmara Carrá}

Mestre em Direito pela UFG. Juiz Federal no Ceará. brunoleonardo5@uol.com.br

Sumário: 1. Dignidade Humana e Responsabilidade Civil. 2. A Vontade como Bem Indenizável: O Projeto de Vida. 3. Projeto de Vida e Dano Moral. Referências.

Resumo: A valorização dos direitos humanos contribuiu, sob muitos aspectos, para a reformulação da própria ideia de Responsabilidade Civil ao longo do Século XX. Lesões pessoais que dificilmente seriam passíveis de repercussão jurídica no passado atualmente gozam de plena proteção legal, e até mesmo possuem tratamento ideológico superior aos chamados danos materiais. Dentro dessa contextura é que se analisa a existência dos danos a um projeto de vida. Em sua estrutura conceitual encontra-se a defesa da liberdade do ser humano sob um enfoque que supera a noção estática de liberdade tal como definido tradicionalmente nos Códigos ocidentais. Se bem que a eventual falta de nomeação explícita por parte da legislação em vigor não possa ser oponível como impedimento ao reconhecimento desses danos, sua compreensão sistemática é medida que se impõe para dar-lhes adequada fundamentação epistemológica.

Palavras-chave: responsabilidade civil. Danos à pessoa. Liberdade e vontade. Existencialismo. Projeto de vida. Reparação. Danos morais.

\section{DIGNIDADE HUMANAE RESPONSABILIDADE CIVIL}

Em sua conhecida tese sobre a "era dos direitos", que constitui o marco epistemológico no qual estamos situados, Norberto Bobbio defende o caráter materialista histórico das conquistas jurídicas dos últimos séculos, as quais tiveram começo já algum tempo atrás. $\mathrm{O}$ autor peninsular deixa claro que, desde as lutas revolucionárias que culminaram com a criação do Estado Moderno, houve uma mudança irreversível na dinâmica das relações de poder, que passaram a ser projetadas não mais sob a 
perspectiva do soberano e sim do cidadão (BOBBIO, 1996. pp. 15-25). Naturalmente, o Estado Moderno já não existe mais como estrutura ideológica. Sem embargo, sua tradição libertária foi não apenas guardada como transmitida para os séculos vindouros que, talvez por terem vivenciado convulsões de intensidade ainda maior, souberam conservá-la e principalmente ampliá-la sob nova dinâmica.

No âmbito do Direito Civil, para além dos campos como o Direito de Família e naturalmente dos Direitos da personalidade, esse complexo cenário importou também a reformulação da própria ideia de Responsabilidade Civil, pois, como assinala Patrice Jourdan, a valorização da pessoa humana conduziu os cidadãos a demandar cada vez mais do Estado-providência (JOURDAN, 2003. p 10).

Somado a esse contexto sociopolítico, ou mesmo até influenciando-o, destaca Jorge Mario Galdós que a tríplice revolução (digital, informática e genética) acontecida ao longo de todo o século XX terminou por, a despeito de todos os imensos benefícios que possibilitou, impactar negativamente sob muitos outros aspectos sob a pessoa humana, dando origem a uma "convergência inescindible de nuevas causas de dañosidad, nuevas técnicas y procedimientos cientificos para identificar otros daños, nuevos bienes jurídicos tutelados, todo lo que amplifica el elenco de las garantías y derechos que tutelan al 'individuo espiritual"' (GALDÓS, 2005 p. 160).

Atualmente, com efeito, eventos que um século atrás dificilmente seriam passíveis de repercussão jurídica hoje não apenas gozam de pronta proteção, como possuem, ademais, dimensão valorativa nitidamente superior aos chamados danos materiais, até algum tempo atrás os únicos indenizáveis pelos ordenamentos jurídicos de tradição liberal ${ }^{1}$. Num simples e feliz arremate, Jorge Mosset Iturraspe diz que a Responsabilidade Civil, que foi construída a partir da noção da culpa, hoje se qualifica a partir do dano, que por sua vez reflete uma intenção não encoberta de privilegiar a vítima no lugar do agressor (ITURRASPE, 2004, p. 37).

Por isso mesmo, ainda de acordo com outros autores, as principais diretrizes da Responsabilidade Civil nos dias presentes podem ser observadas nas seguintes orientações cardiais: a) a extensão dos danos reparáveis; b) a objetivação da responsabilidade civil; c) a prevenção dos danos; d) o aumento da relação de fatores de atribuição; e) a ampliação da legitimidade passiva e ativa em demandas indenizatórias; f) a diminuição para a vítima dos ônus probatórios; g) a socialização gradual dos riscos por meio do seguro obrigatório e da seguridade social (GUTIÉRREZ, 1997, p. 18).

No que diz respeito à proteção da dignidade humana, tal expansão pôde ser sentida, por exemplo, na consolidação daqueles que poderíamos chamar genericamente danos morais, aplicados na França desde o acórdão da Corte de Cassação datado de 25 de junho de 1833. Seja a partir de sua manifestação inicial como danos decorrentes

1 Sobre o assunto cf:: BAPTISTA, 2005; GUTIÉRREZ, 1997; TUNG, 1989. 
de um abalo psicológico, seja na sua atual concepção objetiva de qualquer agressão a algum direito da personalidade, dão inegável testemunho da mudança ideológica sofrida pelas sisudas regras da Responsabilidade Civil.

Mais recentemente, os danos decorrentes do abuso de direito, do dano por ricochete, do dano de ordem genética (ou ao patrimônio genético), do dano estético (quer se reconheça ser ele autônomo ou não ao dano moral), o dano por perda de uma chance e tantos outros representam, igualmente, exemplos cotidianos da crescente expansão de bens juridicamente protegidos tendo como base no respeito à pessoa humana (JOURDAN, 2003. p. 121).

É, assim, possível afirmar com segurança que toda construção legislativa, doutrinária e jurisprudencial acontecida no Século passado em relação aos danos orientou-se no sentido de contextualizar as definições clássicas com as novéis experiências de uma sociedade de massas, o que, por outro lado, também ocasionou em certos casos algum exagero, até mesmo ao limite do rompimento de certos padrões morais².

O exagero, inegável em muitos casos, não pode servir, entretanto, de argumento para sustentar qualquer postura ideológica que defenda uma estagnação, ou mesmo o retrocesso da reconfiguração da Responsabilidade Civil em vista a uma mais eficaz e plena defesa das vítimas.

Se existe o problema da "propagação irracional" dos danos, como também observam Guildo Alpa e Mario Bessone, ele deverá ser resolvido reconhecendo-se que o progresso tecnológico e humanitário vivenciado dentro do século XX produziu uma modificação irreversível no âmbito da reparação civil de modo que se bem nem todo dano possa ser indenizável, pelo menos e cada vez mais os danos e dentre eles os danos sofridos diretamente pelos seres humanos tornam-se bens juridicamente tutelados (ALPA; BESSONE, 2001. p. 5). Para a solução racional e razoável do assunto, portanto, deve medrar uma necessária harmonização entre as normas de responsabilização civil e esses novos bens jurídicos que continuam a surgir, cada vez mais e mais, em uma sociedade cada vez mais dinâmica.

\footnotetext{
2 Destaca-se, especificamente, o caso da jurisprudência que se formou na respeitadíssima Corte de Cassação francesa a partir do chamado "Arrêt Perruche" (Court de Cassation, Assemblée Plénière, 17/11/2000), quando se aceitou a possibilidade de responsabilização civil por erro médico consubstanciado na ausência de informação aos pais de um nascituro que era portador de rubéola. Sendo a interrupção da gravidez admitida na França e havendo o casal Perruche expressamente afirmado que desejaria interromper a gravidez nessas circunstâncias, a Corte de Cassação entendeu que deveriam ser indenizados pelos "prejuízos resultantes dessa deficiência", em função de não terem podido evitar o nascimento da criança. A questão, pela sua intrínseca dimensão moral, ensejou ainda uma série de repercussões legislativas que foram parar na Corte Européia dos Direitos do Homem. Para uma leitura do caso Perruche sob o enfoque multidisciplinar, consultar o "dossier Perruche". Disponível em: <http:// www.senat.fr/evenement/dossier_perruche.html> Acesso em: 25 jan. 2010).
} 
Daí porque assistir razão a Carlos Alberto Ghersi quando afirma que a noção de dano juridicamente reparável vai sofrendo uma ampliação diária, sobretudo por força da realidade socioeconômica e que, em tempos atuais, seria necessária uma revisão das regras da responsabilidade civil para melhor adaptá-la ao momento histórico que vivenciamos, onde tais normas jurídicas precisariam estar fundamentadas em sérias projeções de análise econômica sobre a produção, circulação e comercialização de bens e serviços para não deixar frustradas vítimas em um mundo globalizado (GHERSI, 1996, pp. 29-37).

Dentro dessa complexa contextura (contexto) é que se mostra interessante analisar o predicado dano a um projeto de vida. Em sua estrutura conceitual encontra-se a defesa da liberdade do ser humano, conceito esse que sempre mereceu a atenção dos ordenamentos jurídicos desde o Código Napoleão e que, particularmente no Direito brasileiro, sempre teve sua privação direta indenizável tanto pelo Código Civil de 1916 (art. 1550), embora se discutisse em um primeiro momento a natureza jurídica da reparação, como pelo vigente Código Civil de 2002 (art. 954), agora já sob o manto também do dano moral.

Nada obstante, a ideia de "projeto de vida" e as consequências psicossomáticas que nele são predicadas superam em muito ao estático conceito de privação de liberdade tal como definido tradicionalmente nos Códigos ocidentais.

\section{A VONTADE COMO BEM INDENIZÁVEL: O PROJETO DE VIDA}

Não se pode dissociar liberdade e valorização da pessoa humana, pois traduzem conceitos siameses, onde o menosprezo de um invariavelmente reflete no do outro. Embora costume-se dizer que a vida é o principal dos direitos, pois todos os demais (direitos) começam por ela, não se deve correr o risco de considerar a liberdade como algo a ela inferior. É a liberdade, ou simplesmente a aptidão para ser livre, o traço fundamental que define o ser humano de toda e qualquer espécie animada. Vida, sem liberdade, já não é vida humana.

É pela valorização da liberdade que se chega, finalmente, ao conceito de dignidade da pessoa humana, ou, simplesmente, dignidade do homem. De todos os animais, apenas o homem possui liberdade e, ainda mais importante, a consciência dela, que o faz sofrer pela sua privação, quando ela vem a ser atacada, ou de algum modo diminuída.

Um expressivo e pioneiro exemplo da defesa política do homem e de sua liberdade pode ser encontrado na Oratio de Hominis Dignitate de 1486. Aí, Giovanni Pico della Mirandola já postulava o irrestrito respeito à liberdade, na medida em que a plenitude do ser humano somente poderia ser atingida com seu irrestrito respeito. Por outro lado, o ultraje à plenitude do ser humano consistiria verdadeira estultice na medida em que privaria a admiração de todas as facetas desse "nosso camaleão", que em tudo poderia transformar-se se lhe fossem garantidas condições suficientes para seu florescimento e desenvolvimento (PICO DELLA MIRANDOLA, 1989. p. 52). 
As conexões entre direito e liberdade puderam ser sentidas com maior intensidade neste último século, onde, na correta explicação de Jorge Mosset Iturraspe, a constituição do dano à pessoa apareceu como resposta a toda uma corrente personalista ou existencialista do Direito que, como "um novo renascimento volta a colocar a pessoa humana como eixo ou centro das preocupações jurídicas" (ITURRASPE, 2004, p. 281).

Com esse cenário por pano de fundo é que Carlos Fernánez Sessarego vem a desenvolver sua tese sobre os danos ao projeto de vida. Diz esse respeitado professor peruano que as pessoas não podem simplesmente ser tratadas sob um aspecto puramente estático no que se relaciona ao exercício de sua liberdade. O caráter intrinsecamente libertário do ser humano impõe, em última análise, que a liberdade seja levada em consideração pelo ordenamento jurídico como valor e bem passível de ser apreciável a título, também, de reparação civil em face de seu caráter dinâmico:

Pues bien, después de lo dicho cabe preguntarse una vez más si existe un " proyecto de vida". Por nuestra parte, desdeantiguo, estamos convencidos de ello porque, fundamentalmente, vivenciamos nuestra libertad y sabemos de nuestros proyectos, de lo que hemos elegido realizar en la vida para otorgarle sentido, y de la valoración vocacional queello significa. E s decir, somos conscientes de que existe una razón para vivir. Lo que no es poco, si apreciamos en todo su valor y significación el precioso don de la vida.

D espués de lo hasta aquí expresado es lícito preguntarse si es posible causar un daño que frustre nada menos que el proyecto de vida de la persona. D e ello estamos plenamente convencidos, pero lo que pretendemos intentar con estas reflexiones es contribuir en la tarea de precisar los alcances y la importancia de una protección plena e integral del ser humano en todo lo que él significa y representa (SESSAREGO, 1996, p. 19).

Ao proteger a liberdade dos seres humanos, o ordenamento jurídico estaria protegendo e resguardando o direito que cada ser humano tem de realizar seu pessoal "projeto de vida", aí excluídas, claro, as condutas ou projetos tendentes a ofender a moral, os bons costumes, a ordem pública, ou, simplesmente, venha prejudicar aos demais.

A explicação faz-se necessária para que não se venha a autorizar a conclusão no sentido de que qualquer projeto de vida seja permitido pelo ordenamento jurídico e, assim, possa ser constituído como um prejuízo indenizável, porque há, como sabido, uma confluência entre os conceitos de liberdade e responsabilidade, de modo que a garantia que se outorga para seu uso pressupõe, como não poderia ser diferente, um agir responsável. Como outros conceitos dialéticos (e talvez mais que todos) na definição mesma de liberdade estão incorporados elementares de responsabilidade e respeito à liberdade alheia, quer seja individual ou coletiva.

Com efeito, trata-se de conhecida lição proferida por Sartre: 


\begin{abstract}
Porém, se realmente a existência precede a essência, o homem é responsável pelo que é. Desse modo, o primeiro passo do existencialismo é o de por o homem na posse do que ele é e de submetê-lo à responsabilidade total de sua existência. Assim, quando dizemos que o homem é responsável por si mesmo não queremos dizer que o homem é apenas responsável pela sua estrita individualidade, mas que é responsável por todos os homens (SARTRE, 1987, p. 6).
\end{abstract}

Logo, a liberdade que é juridicamente protegida é a liberdade individual em harmonia ou sintonia com o outro. Em possíveis termos heideggardianos, poder-se-ia dizer que a liberdade protegida pelo ordenamento jurídico é a liberdadecom, que reflete a legítima formação do caráter humano em companhia com seus semelhantes ("das dasein") e não a liberdadecontra que se dirige, justamente, em reprimir ou privar a liberdade existencial dos demais indivíduos.

Não há dúvidas, como já referido, que os ordenamentos jurídicos de cunho ocidental vêm outorgando ao valor liberdade um zelo especial. Não se trata de defender a liberdade atrelada questões puramente econômicas, como a liberdade contratual, que, paradoxalmente, até experimenta uma diminuição em virtude de toda uma legislação imbuída de profundo viés público, como, por exemplo, a que regulamenta a proteção e a defesa dos consumidores e que pode chegar ao extremo de determinar situações de contratação obrigatória.

A incidência da dimensão existencial do Direito sobre as regras da responsabilidade civil dão um enfoque destinado, portanto, a toda uma projeção inercial que se tinha da liberdade humana. Não é a simples privação da liberdade que se almeja indenizar ou reparar; não é tão somente a dor psicológica sentida pelo sentimento de impotência resultante de tal privação, mas sim a justa reprimenda que deve ser imposta a quem frustra ou impede de se permitir a realização de um projeto humano.

Repousam aí as premissas fundamentais da obra de Carlos Fernández Sessarego, para quem os danos à pessoa são divididos em apenas duas categorias: a) danos psicossomáticos; b) danos a um projeto de vida.

Na primeira categoria de danos incluem-se toda e qualquer lesão sofrida pelo soma, isto é o corpo em seu sentido estrito, nela incluída a "psiquê". A junção dos danos estritamente fisicos com os danos à "psiquê" é justificada porque o homem constitui uma unidade incindível, de forma que "os danos somáticos repercutem, necessariamente e em alguma medida na psique e os danos psíquicos, por sua vez, geram repercussão somática" (SESSAREGO, 1996, p. 18).

Naturalmente, o que estamos acostumados a chamar de dano moral também é visto como uma forma de dano psicossomático, na obra desse autor peruano. Por conseguinte, todas as novas espécies de danos, cujos conceitos estão intrinsecamente atrelados a uma repercussão lesiva sobre o corpo do indivíduo, igualmente passam a ser classificados como danos psicossomáticos, tais como o dano biológico, o dano estético, o dano à saúde, o dano genético etc. 
Por outro lado, a liberdade ontológica, em virtude de seu especial papel para o desenvolvimento dos seres humanos, desafia reparação autônoma, acaso violada. É esse dano à liberdade fenomênica, ou em uma palavra, à vontade que se procura reconhecer e sancionar sob a noção de dano a um projeto de vida. A vontade deve ser livre, plenamente livre, para satisfazer um projeto de vida, ou, sendo o caso, mesmo não o querer realizado, mas sempre deverá ser uma decisão livre, o que já é algo bem limitado em razão das atávicas correlações biogenéticas do ser humano, como já ensinava, dentre outros filósofos modernos, Luis Recasén Siches³.

A diferença entre o dano psicossomático e o dano ao projeto de vida surge quando é colocado em relevo o elemento vontade. Constituir-se o dano psicossomático como um dano que deixa marcas, quer no corpo, quer na alma (moral), mas não atrapalha necessariamente que a vítima possa, mercê de suas forças volitivas, prosseguir sua jornada existencial e vir a realizar-se enquanto ser humano. $\mathrm{O}$ dano ao projeto de vida, ao contrário, pressupõe essa privação de ordem substancialmente volitiva, no qual é constituído. Uma vez mais, as palavras de Carlos Sessarego:

es oportuno señalar que si bien el ser humano es una 'unidad psicosomática constituida y sustentada en su libertad', se suele confundir, frecuentemente, la libertad, que es el ser mismo del hombre, con la unidad psicosomática en la que ella está implantada o con un particular aspecto o función dela misma. E sta confusión es más notoria tratándose de la voluntad, que es una de las vertientes psíquicas, sin percatarse que ésta se halla, como la unidad psicosomática en su conjunto, al servicio del 'yo', del ser mismo, de su decisión libre. La envol tura psicosomática es un medio o instrumento del cual se vale la libertad para su realización como proyecto (SESSAREGO, 1996. p. 44).

Em suporte às ideias de Carlos Sessarego, não seria equivocado tomar emprestado, dentre outros filósofos, o respeitado pensamento de Hannah Arendt que afirmava: "pensar y recordar, hemos dicho, es la manera humana de echar raíces, de ocupar el propio lugar en el mundo, al que todos llegamos como extraños. Lo que solemos llamar persona o personalidad, como algo distinto de un simple ser humano o de un nadie, brota efectivamente del enraizamiento que se da en este proceso de pensamiento." (ARENDT, 2007, p. 115).

Deste modo, pretende-se esclarecer que para a construção do eu de cada indivíduo, é necessário que haja toda uma zona formada tanto por projeções (futuro) como por recordações (passado), que dialeticamente se miscigenam até formar o presente, ou seja, o eu que efetivamente existe e que, então, torna-se objeto de ação.

\footnotetext{
3 "Vida significa la forzosidad de realizar el proyecto de existencia que cada cual es. Este proyecto en que consiste el yo, no es una idea o plan ideado por el hombre y libremente elegido. Es anterior a todas las ideas que su inteligencia forma, a todas las decisiones de su voluntad. Más aún, de ordinario no tenemos de él sino un vago conocimiento, y, sin embargo, es nuestro auténtico ser, nuestro destino. Nuestra voluntad es libre para realizar o no ese proyecto vital que últimamente somos, pero no puede corregirlo, cambiarlo, prescindir de él o sustituirlo" (SICHES, 2008, pp. 252-253).
} 
Os elementos de índole puramente somática são, na opinião de Hannah Arendt, inclusive dispensáveis para a definição da personalidade do ser humano, na medida em que:

[.... ] la cualidad de ser persona, como distinta del simple ser humano, no figura entre las cualidades, dones, talentos o defectos individuales con que nacen los hombres, y de los que pueden usar 0 abusar. La cualidad personal de un individuo es precisamente su cualidad 'moral', si no tomamos la palabra en su sentido etimológico ni en su sentido convencional, sino en el de la filosofía moral (ARENDT, 2007, p. 98).

Por decorrência, não se trata de indenizar, a título de dano a um projeto de vida qualquer frustração ocasional, como a decorrente de um atraso, ou um dissabor qualquer. Estas continuam a ser indenizadas pelas formas próprias, as quais, no nosso Direito positivo, têm previsão explícita nas regras dos artigos 186, 953 e 954 do Código Civil.

Por outro lado, apenas situações de extrema gravidade é que teriam guarida sob título de dano a um projeto de vida, que possui sempre configuração de dano futuro, por significar a perda ou a diminuição da vontade enquanto elemento anímico que nos orienta à realização de um projeto egológico ${ }^{4}$. A perda da vontade, ou sua obliteração em condições juridicamente indenizáveis, como demonstram as regras ordinárias da experiência, não se faz por atos de menor dimensão. Um contratempo, é certo, sempre terá impacto sobre a vontade humana, mas a existência é formada também por tais dissabores e angústias. $\mathrm{O}$ ser humano, em princípio, naturalmente não se rende a eles e, por não se render, como no mito grego de Prometeu, é que inventou a aventura humana.

A eventual falta de nomeação explícita por parte da quase totalidade dos ordenamentos jurídicos, outrossim, não pode ser entendida como impedimento oponível ao seu reconhecimento, já que, embora seja certo que não houve ainda a ruptura do marco teórico que propugna que os direitos somente são indenizáveis quando juridicamente protegidos (danos juridicamente apreciáveis), não é menos certo que a descrição "numerus clausus" das sanções reparatórias, da qual a mais autorizada representante foi a hermética escola da Exegese, deu lugar definitivamente, ainda no Século passado, a um sistema topográfico e maleável de atribuição de responsabilidades civis tendo por base o elemento principiológico que anima a criação do Direito.

No caso brasileiro, pode-se afirmar, com relativa facilidade, que o dano ao projeto de vida, na medida em que representa uma agressão concreta à liberdade de um ser humano, deva ser indenizado com fundamento no artigo 186 do Código Civil de 2002 e ainda do próprio texto constitucional de 1988, ou seja, na condição de dano moral.

\footnotetext{
${ }^{4}$ Ou seja, um projeto relativo a própria conduta humana: "P ero hay otros objetos culturales cuyo substrato es la propia acción o conducta humana; ahora se trata de la corporización de un sentido que es el sentido del comportamiento humano [... ] L lamamos a éstos objetos egológicos, porque siendo conducta el substrato de ellos, la conducta es inseparable del ego actuante: en el substrato de estos objetos hay un ego como ego" (COSSIO, 2007, p. 64).
} 
Tal conclusão, entretanto, longe de pacificar a questão, na verdade faz é aprofundá-la. Isso porque, em sua construção original, Carlos Sessarego recusa-se a admitir que os danos ao projeto de vida consistam em espécie ou modalidade de dano moral, compelindo a um exame sistemático desses danos como medida necessária para darlhes adequada fundamentação epistemológica, em cujo teste, efetivamente, poder-se-á descobrir suas verdadeiras raízes ontológicas.

\section{PROJETO DE VIDAE DANO MORAL}

Desde 1998 a Corte Interamericana de Direitos Humanos tem articulado pronunciamentos onde é explícita a referência a essa modalidade de danos, os quais, por conseguinte, mereceram efetiva reparação jurídica nos termos do Pacto de São José da Costa Rica.

O dano a um projeto de vida é definido pela Corte como um atentado contra a realização pessoal do indivíduo afetado, considerando sua vocação, atitudes, circunstâncias, potencialidades e aspirações, que lhe permitam fixar, de forma razoável, determinadas expectativas e alcançá-las. Enfim, como restou precisado no chamado caso "Maria Elena Loayza Tamayo contra o Estado peruano", uma redução objetiva da liberdade fenomênica5.

Partindo-se, assim, da premissa de que o dano ao projeto de vida tem como fundamento uma agressão séria à liberdade fenomênica dos indivíduos, é dizer, sua vontade pode-se, portanto, sistematizá-lo em três subespécies distintas: a) danos que frustram parcialmente um projeto de vida; b) danos que se manifestam em um retardamento na realização de um projeto de vida; c) danos que determinam a frustração completa de um projeto de vida.

Há, portanto, que saber dimensioná-las concretamente. Não se pode exigir, de um lado, que apenas casos extremos, como os que se relacionam a própria morte da vítima, permitam a incidência de tais danos. Por outro lado, não é também qualquer desmotivação passageira que irá autorizar sua aplicação.

\footnotetext{
5 Nesse sentido, consultem-se as seguintes decisões, todas da Corte Interamericana de Direitos do Homem: caso "Maria Elena Loayza Tamayo Vs. Peru", de 27 nov. 1998; caso de "Los Niños de La Calle Vs. Guatemala"; de 26 maio 2001; caso de "Cantoral Benavides Vs. Peru", de 3 dez. 2001; Caso "del Caracazo Vs. Venezuela", de 29 ago. 2002; Caso "Maritza Urrutia Vs. Guatemala”, de 27 nov. 2003; caso "Molina Theissen Vs. Guatemala", de 03 jul. 2004; Caso de "los Hermanos Gómez Paquiyauri Vs. Perú", de 08 jul. 2004; Caso "Carpio Nicolle y otros Vs. Guatemala", de 22 nov. 2004; Caso de "las Hermanas Serrano Cruz Vs. El Salvador", $1^{\circ}$ mar. 2005; Caso "Gutiérrez Soler vs. Colombia”, de 12 set. 2005; Caso "del Penal Miguel Castro Castro Vs. Perú", de 25 nov. 2006; Caso de "la Masacre de La Rochela Vs. Colombia”, de 11 mar. 2007; Caso "Cantoral Huamaní y García Santa Cruz vs. Perú", de 10 jul. 2007; Caso "Valle Jaramillo y otros vs. Colombia", 27 nov. 2008.
} 
Assim, o defendido dano ao projeto de vida, sem embargo de seu reconhecimento como espécie própria de agressão a um bem jurídico reconhecido pelo ordenamento jurídico, não pode ser compreendido como um elemento autônomo para fins de fixação da indenização civil. As propostas lançadas por Carlos Fernández Sessarego, a despeito de toda sua originalidade, nesse ponto dão provas de um corte epistemológico arbitrário que, com as mais respeitosas vênias, não guarda simetria com a realidade existencial na qual ele se inspira.

A liberdade que é violada e que dá ensejo à frustração ao projeto de vida é obviamente um elemento somático, como não poderia deixar de ser. Não há que se dizer que o soma seja um instrumento da liberdade, como que estabelecendo uma gradação artificial entre eles, senão que a liberdade ela própria também está indiscutivelmente associada ao soma. Por outro lado, ainda que projetada para o futuro, a frustração aos sonhos e anseios de uma pessoa dificilmente poderá ser concebida sem qualquer repercussão psicossomática.

O próprio autor peruano afirma que todo dano a um projeto de vida tem como antecedente um dano psicossomático. Parece, assim, ser invencível a contradição que vai se seguir quando, logo após, é sustentada uma alteridade categórica entre ambos os conceitos (dano psicossomático e dano a um projeto de vida).

É preciso ter-se em conta que não apenas a frustração de um projeto de vida mas igualmente (talvez até mesmo em maior medida) que a própria realização dele em função do exercício mais pleno da liberdade acarreta ao indivíduo profunda carga de stress emocional que repercute invariavelmente sobre seu corpo, ou sua saúde. Realizar ou não realizar um projeto de vida, qualquer que seja a razão, legítima ou ilegítima para tanto, sempre apresentará algum grau de repercussão sobre o corpo do indivíduo, o que afasta qualquer possibilidade de tratar a ambos separadamente.

Encarreguemos, portanto, a ninguém menos que Eric Fromm o arremate dessa nossa afirmação:

¿Puede haber idea más simple? Ú nicamente la forma de vida más superficial, más enajenada, puede no exigir decisiones conscientes, pero sí provoca multitud de síntomas neuróticos y psicosomáticos, como las úlceras y la hipertensión, que son manifestación de conflctos inconscientes. Q uien no haya perdido por completo la capacidad de sentir, quien no se haya convertido en un robot, no podrá evitar el afrontar decisiones dolorosas (FROMM, 2007, p. 93).

Perceba-se que não se está, de forma alguma, pugnando pela falta de sentido ou que se advoga o caráter prescindível da noção de dano a um projeto de vida. $\mathrm{O}$ dano à liberdade deve sim ser considerado como uma forma de dano a ser especialmente considerado quando presentes as elementares que autorizam sua concreta configuração. Nada obstante, e diferentemente da linha metodológica desenvolvida por Carlos Fernández Sessarego, não consideramos que as categorias dano a um projeto de vida e dano psicossomático suplantem a já clássica categoria dano moral, porquanto nela ainda existem peculiaridades que não apenas tornam reais os prejuízos imateriais decorrentes 
da frustração a um projeto de vida, como, inclusive, ajudam a divisar-lhe um sentido e um limite razoável.

Consideradas tais deficiências epistemológicas da classificação proposta por Carlos Fernández Sessarego, a categorização dos danos encontrada na obra dos Mazeaud e Chabas pode representar uma solução cientificamente mais adequada para a compreensão e sistematização do dano ao projeto de vida, o qual não deixaria de estar vinculado ao chamado prejuízo moral, dele não se apartando, porém, redimensionando-o.

Os consagrados autores franceses partem do pressuposto que a classificação dialógica entre dano material e dano moral, realmente não pode mais ser empregada em virtude do caráter absolutamente distinto ("tercius genus") do chamado dano corporal ("dommage corporel"), que, por isso mesmo, passa a ter uma dimensão própria.

O dano corporal é definido como um méo-caminho entre o dano material e o dano moral, pois cuida de perdas que vão além da objetividade estrita que caracteriza o dano material por englobar justamente as ofensas à integridade física da pessoa, esse fino material que, por influxo dos valores que dão forma ao que se denomina Direito ocidental, merece superior atenção. Por outro lado, não se pode considerar como agressão puramente imaterial, vez que deixa seqüelas no mundo sensível.

Em sendo assim, o dano corporal trata das ofensas fisicas à pessoa, traduzindo-se, principalmente, pela incapacidadetemporária total e pela incapacidadepermanenteparcial (e algumas vezes pela incapacidade parcial temporária). Dentro dessa perspectiva são indenizáveis tanto os danos puramente físicos, como os incidentes pecuniários decorrentes dos ferimentos sofridos, ainda que ela não tenha profissão, ou tenha sofrido perda de seus rendimentos (MAZEAUD; MAZEAUD; MAZEAUD; CHABAS, 1998, p. 413).

Nisso o dano corporal se diferencia do dano estritamente material, que, inclusive, pode ter incidência mesmo diante de agressões contra a integridade corporal de alguém. É o caso, justamente, daquelas circunstâncias onde as lesões impostas à pessoa geram reflexos estritamente pecuniários, como exemplificam o pagamento dos honorários médicos e demais custas hospitalares, bem como a perda de renda propriamente dita em função de uma agressão corporal (MAZEAUD; MAZEAUD; MAZEAUD; CHABAS, 1998, p. 422).

Por isso, advogam esses renomados autores que as espécies de danos deveriam ter uma divisão tripartite e, assim, deveriam ser tratados por: a) danos materiais; $\mathrm{b}$ ) danos corporais; c) danos morais. A propósito, para o Direito Francês, essa separação não é apenas doutrinária, uma vez que seu Código da Seguridade Social alude, pelo menos indiretamente, a prejuízos corporais (físicos) e morais, como pode ser visto da leitura de seu art.454-I.

Separado do dano corporal, que poderia ser conceituado como dano fíicamente sensível, isto é, que tem repercussão estritamente física, o dano moral apresenta-se como lócus de incidência de todos os demais danos que afetam a existência anímica propriamente dita, ainda que tenha projeções psicossomáticas. O elemento que serve de que 
é a origem. Se a consequência psicossomática está associada a fatores de perturbação de origem puramente emocional, devem ser indenizados como danos morais e não propriamente como danos corporais, salvo se as intercorrências danosas forem de tal expressão que também se projetem sobre o corpo, nele deixando marcas ${ }^{6}$.

Interessante destacar que, sob essa nova perspectiva, a noção de dano moral torna-se visivelmente mais ampla. Capaz de albergar situações antes havidas como simples desfrute, que não convinha à ideia de homem trabalhador, ou homem produtor ("homo fabris") então em voga. Atualmente, portanto, existe uma perfeita consciência de que da gravidade de qualquer desrespeito, corporal ou espiritual, à integridade biológica dos seres humanos, bem como que "la apetencia respecto del goce de la vida, del estado de la salud, de la 'alegría de vivir' no son ya patrimonio de uma clase social o de grupos determinados, alcanza a todos los miembros de la comunidad" (ITURRASPE, 2004, p. 318).

Assim redimensionado o conceito de dano moral, torna-se possível, sem qualquer entrave reducionista, nele implantar a ideia de dano a um projeto de vida como uma de suas muitas espécies, como são o dano ao bem-estar, ou os de natureza afetiva concebidos há muito tempo pela jurisprudência francesa. Tal solução a nosso ver tem a dupla função. Em primeiro lugar, reafirma a vontade humana, enquanto elemento formatador de sua liberdade fenomênica, como bem jurídico sedento de merecer o tratamento que lhe corresponde pelas regras da responsabilidade civil ao passo que, por outro lado, não procura distorcer a lógica dos institutos jurídicos em vigor, mas tão somente harmonizá-los com o mundo em que vivemos hoje.

${ }^{6}$ Por tal razão é que a Corte de Cassação considera o dano sexual relacionado com a frigidez ou a impotência masculina como um caso de "préjudice d'agrément" (dano ao bem-estar) e como tal o indeniza a título de dano moral e não propriamente dano corporal, salvo quando, como informado, com a disfunção orgânica é acompanhada alguma forma de lesão estética (Cf. MAZEAUD, MAZEAUD; MAZEAUD; CHABAS, 1998, p. 426). 


\section{REFERÊNCIAS}

ALPA, Guido; BESSONE, Mario. La Responsabilità Civile. 3. ed. atual. por Pietro Maria Putti. Milano: Giuffrè, 2001.

ARENDT, Hannah. Responsabilidad y Juicio. Trad. de Miguel Canel e Fina Birulés. Barcelona: Paidós, 2007.

BAPTISTA, Silvio Neves. Teoria Geral do Dano: de acordo com o novo código civil brasileiro. São Paulo: Atlas, 2005.

BOBBIO, Norberto. L'Età dei Diritti. 8 reimp. Turim: Einaud, 1996.

COSSIO, Carlos. Teoría de la Verdad Jurídica. Buenos Aires: El Foro, 2007.

FROMM, Eric. Del Tener al Ser. caminos y extravíos de la conciencia. Trad. de Eloy Fuente Herrero. Barcelona: Paidós, 2007

GALDÓS, Jorge Mario. Nuevos Daños a la Persona em la Sociedad de Riesgo. In Kemelmajer de Carlucci, Aída; Represas, Félix Alberto Trigo; Costa, María Josefa Méndez (coord.). Edición Homenaje Jorge Musset Iturraspe. Santa Fé: Universidad Nacional del Litoral, 2005.

GHERSI, Carlos Alberto. El Ser Humano y la Dañosidad como Inevitable Contingencia Social. In GHERSI, Carlos Alberto et allí. Responsabilidad: Problematica Moderna. Mendonza: Ediciones Jurídicas Cuyo, 1996.

GUTIÉRREZ, Graciela N. Messina de Estrella. La Responsabilidad Civil en La Era Tecnológica. tendências y prospectivas. Buenos Aires: Abeledo-Perrot, 1997

ITURRASPE, Jorge Mosset. Responsabilidad por Daños. parte general. Buenos Aires: Rubinzal Culzoni, 2004. t. I.

JOURDAN, Patrice. Les Principes de la Responsabilité Civile. 6 ed. Paris: Dalloz, 2003.

MAZEAUD, HENRI; MAZEAUD; Léon; MAZEAUD, Jean; CHABAS, François. Leçons de Droit Civil - obligations theorie générale. 9 ed. Paris: Montchrestien, 1998. t II. v. 1

PICO DELLA MIRANDOLA. Discurso sobre a Dignidade do Homem. Trad. Maria de Lurdes Sirgado Ganho. Lisboa: Edições 70, 1989.

SARTRE, Jean Paul. O Existencialismoé um Humanismo(Col. Os Pensadores). Trad. de Rita Correia Guedes. 3 ed. São Paulo: Nova Gultural, 1987. [1-32].

SESSAREGO, Carlos Fernández. Apuntes para la Distinción entre el Daño al Proyecto de Vida y el Daño Psíquico. In Los Derechos del Hombre daños y protección a la persona. Mendonza: Ediciones Jurídicas Cuyo, 1996. p. 19. 
SICHES, Luis Recásens. Filosofía del Derecho. 19 ed. Cidade do México: Porrúa, 2008.

TUNC, André. La Responsabilité Civile. 2. ed. Paris: Economica, 1989.

\section{DAMAGESTO A LIFE PROJECT?}

Abstract: The appreciation of the human rights has contributed, in many ways, for the reformulation of the very idea of torts over the twentieth century. Injuries or harms that could hardly have legal repercussions in the past, currently enjoy full legal protection, and even counting with some sort of superior ideological treatment than merely monetary losses. Within this texture, we approach the so-called "life project damage". In its conceptual framework is the defense of human freedom from a perspective that goes far away from the static notion of freedom as defined traditionally in the western codes. Although the lack of an express appointment by the existing legislation cannot be invoked as a reason to not endorse the recognition of such damages, it still demands a systematical understanding in order to give these damages a proper epistemological perspective.

Keywords: Tort Law. Personal Injuries. Freedon and will. Existentialism. Life Project. Liability. Pain And Suffering. 